\title{
The Assessment of Berth Occupancy Ratio (BOR) to Achieve Required Standardised Level and Optimum Throughput: A Case of Oil and Gas Terminal in Kalimantan
}

\author{
Raja Oloan Saut Gurning, Fauzan Fikri \\ Jurusan Teknik Sistem Perkapalan, Fakultas Teknologi Kelautan, Institut Teknologi Sepuluh Nopember (ITS) \\ Surabaya Jl. Arif Rahman Hakim, Sukolilo, Indonesia \\ $\underline{\text { sautg@its.ac.id }}$
}

\begin{abstract}
Abstrak
In many cases of berth occupancy (BOR) level in the port can be one of the factors considering whether the services of port is busy or not. Later, the factors are evaluated including operational, technical or any other thing that makes this parameter to rise and affect the performance of the services of a port . In this study, the BOR assessment is applied by modeling the existing operation of an oil gas and terminal in Kalimantan using ARENA to fulfill fuel oil (BBM) and gas in the eastern part of Indonesia. The model considers various factors as the terminal service capacity and the input of terminal traffic such as increased cargo balance from time to time including ships and cargo traffic. To support the implementation of the terminal acceleration program, the analysis of utility usage dock and equipment loading - unloading (marine loading arms) is an essential item for giving arguments plans facility expansion due to the increasing traffic of ships and the cargo services through a strategic plan providing such as new facilities/equipments and other new managemet arrangement. As a result, the study may provide scenarios as options for the terminal operator to implement in achieving both the optimised throughput and acceptable BOR level by considering operational, technical, commercial and management strategies.
\end{abstract}

Keywords: Berth occupancy ratio, assessment, oil and gas terminal, Kalimantan

\section{BACKGROUND}

In order to fulfill of fuel oil (BBM) in the country increased from time to time, the company intends to increase oil production in Balikpapan with Refinery Development Master Plan Program. To support the implementation of the project, the analysis of utility usage dock and equipment loading - unloading (marine loading arms) is an essential item for giving arguments plans facility expansion of the terminal due to the increasing traffic of ships and the cargo services through plan providing new facilities, especially for offshore and pipeline. As for the initial Plan for the terminal, assessment in measuring existing port performance is required [1]. The assessment process occupancy or use of the Jetty determined from various aspects of both technical and operational jetty from various factors such as cargo types, the type of efficient transport fleet is based on a scale of volume of cargo offered, the amount of the jetty provided along with the number of moorings [2]. Once the movement of the ship at the jetty then the total time a vessel in that jetty can be estimated and usually known as turn round time or the acronym is TRT ). Further, a ship allowed to enter and exit the harbor area through arrangements made by KSOP (Kepala Syahbandar Otoritas Pelabuhan). In addition, another important thing is the loading and unloading equipment (marine loading arms ) and utilities should be ensured to be available. Based on the background explained, there are complexity to get an assessment of the use of occupancy of the jetty, with the destination of developing a system of representation becomes much simpler to be analyzed as well in the process when needed improvement scenarios to get an assessment of the effective BOR to fulfill increasing fuel production in the terminal with RDMP acceleration program. Therefore, in this study, a simulation modeling of the entire all system is required. Given the framework of undertaking the process as explained above, this study consequently will have some stages of the work processes, i.e: started from data collection, data processing and build the existing models, verification and validation of the model, build scenario models, analysis and implement the model results.

\section{METHOD USED}

Before building the model by software, first, we have to build a conceptual model, so that the logic of modeling does not let an error. For the detail the conceptual model can be seen in Figure 1 below. 
Table 1: Jetty arrangement of the terminal

\begin{tabular}{|c|c|c|c|c|}
\hline \multirow{2}{*}{ No } & \multirow{2}{*}{ Type of Berth } & $\begin{array}{c}\text { Dept alongside } \\
\text { berth }\end{array}$ & \multicolumn{2}{|c|}{ Restriction of vessel's size } \\
\cline { 4 - 5 } & & 9.5 & Max DWT & $\begin{array}{c}\text { Max LOA } \\
(\mathbf{m})\end{array}$ \\
\hline 1 & Jetty No.1 & 10 & 36,000 & 165 \\
\hline 2 & Jetty No.2 & 12 & 20,000 & 165 \\
\hline 3 & Jetty No.3 & 12 & 36,000 & 195 \\
\hline 4 & Jetty No.4 & 11 & 36,000 & 185 \\
\hline 5 & Jetty No.5 & 5 & 5,000 & 110 \\
\hline 6 & Jetty No.5A & 13 & 36,000 & 160 \\
\hline 7 & Jetty No.5B & 12.6 & 36,000 & 190 \\
\hline 8 & Jetty No.5C & 12 & 35,000 & 213 \\
\hline 9 & Jetty No.6 & 10 & 10,000 & 120 \\
\hline 10 & Jetty No.7 & & & \\
\hline
\end{tabular}

In this conceptual model, it is starting with clustering of each vessel based on size of DWT, where previously have been discussed. Furthermore, based on the stage of data processing that has been done, we get for each cluster ship to check each jetty to be idle or not, the vessel will enter when jetty empty, then will be in the process of berthing, transferring, and unberthing. The process that occurs at each jetty have to be calculated into the turn round time [3], [4], whereby these results with the factor of time total docking in one year and the number of moorings in the terminal will be used as a factor for The BOR calculations as seen in Figure 1 below.

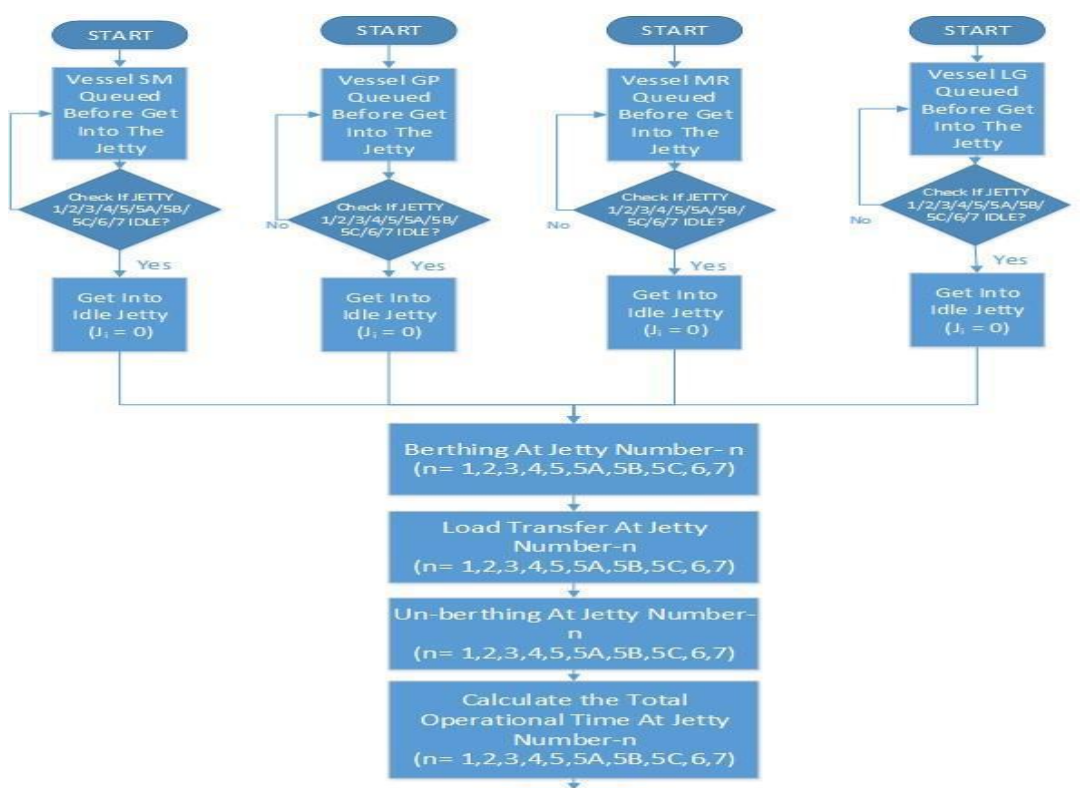

END

Figure 1. The flow chart of simulation process

For the detail of BOR calculation, can be seen on the formula:

$\mathrm{BOR}=\frac{\text { VsxSt }}{\text { Effective Timexn }} \times 100 \%$

with

BOR : Berth Occupancy Ratio (Soberon 2012)

Vs $\quad:$ Total of ships served (unit/year)

St $\quad$ : Service time (hours/day)

$\mathrm{N} \quad$ : total of moorings

Effective time : total of docking time in one year 


\section{MODELING AND SCENARIOS RESULTS}

The running result of existing model shows the actual condition of BOR at each jetty. Based on the recommendation of UNCTAD, BOR value above $60 \%$ is categorized as "high", while value below $60 \%$ is categorized as "low". On the result of the existing model, almost the entire jetty in the category of high BOR. The highest BOR in the category of "high" is jetty number 2 with a value of $79 \%$ while the lowest is jetty number $5 \mathrm{C}$ with a value of $61 \%$. The BOR value for category "low" is jetty number $5 \mathrm{~A}$ with a value of $33 \%$. Several scenarios have been set at the beginning will be made as experiment to do some improvement at each jetty. The best scenario is a scenario that can generate "low" BOR value at each jetty.

Table 2. BOR value of existing condition at each jetty.

\begin{tabular}{|cccc|}
\hline \multicolumn{4}{|c|}{ Existing Operation } \\
\hline Jetty & $\begin{array}{c}\text { Total Round } \\
\text { (hour) }\end{array}$ & BOR & $\begin{array}{c}\text { BOR } \\
\text { Category }\end{array}$ \\
\hline 1 & 6254 & $77 \%$ & High \\
2 & 6449 & $79 \%$ & High \\
3 & 5459 & $67 \%$ & High \\
4 & 5206 & $64 \%$ & High \\
5 & 5929 & $73 \%$ & High \\
$5 \mathrm{~A}$ & 2671 & $33 \%$ & Low \\
$5 \mathrm{~B}$ & 5899 & $72 \%$ & High \\
5C & 4986 & $61 \%$ & High \\
\hline Total & 42853 & $66 \%$ & \\
\hline Cargo & 17.153 .512 & & \\
\hline
\end{tabular}

In this study, there are several considerations in determining the value of BOR in the terminal, among others, the first value is BOR allowed by UNCTAD [5] has a maximum value of BOR 60-65 percent, the second consideration to continue to anticipate the rising volume of cargo handling oil and gas that can be handled the terminal in the future [6]. The third, a value BOR high large potential cause various additional costs, especially the cost of waiting time that will be new problems not only for the terminal as an operator, but also public service users who wants a gas distribution process more efficient and effective, and therefore in addition to trying to evaluate from existing models that have been made, also required a system model scenarios in the terminal activity. Where in these scenarios, trying to give an option to obtain an effective value of BOR to fulfill considerations mentioned above. By sampling conducted from January-April 2016, there were approximately 457 hours as a vessel total waiting time due to various problems, obstacles, or lack of jetty facilities and operation management. In addition, from the model reselts can also inform that jetty number 2, 3, 4, and 5 needs a special concern. Mainly jetty number 4 has a dominant waiting time constraint compared to other jetties. Though, several inhibiting factors or waiting time occurs in all jetties. The main factor of high waiting time in jetty number 4 is caused by waiting for availability of jetty number 4 when it still utilized by another ship. While other minor factors are caused by waiting for document, the amount of cargo, cargo calculation, laboratory analysis, wait for a pilot, and low pace of pump including MLA. Hence, Jetty number 4 need to be a main concern in development of te terminal in the future especially with increasing demand for crude oil cargo, LSWR, aviation fuel, kerosene, premium, HOMC, HSD, MFO, ADO, Afigas, Naptha, and HVGO. The indication of high waiting time in jetty number $2,3,4$, and 5 seems comparable to BOR level owned by each jetty. It can be ascertained that the high BOR value in four jetties fundamentally caused by high waiting time. From the observation during the survey, the root cause of the problem may be due to low carrying capacity of the infrastructure, especially the pier or jetty and loading-unloading equipment (MLA). However, it also can be caused by soft-structure in the form of various ways of managing or arrangement and the use of ICT technology in accelerating document process or monitoring various operational activities. With a determined the amount of cargo 32 million tons, then the next stage is to discuss how simulation scenarios that try used to be the fulfillment of these options, and for details on the scenarios that have been defined can be seen in Table.3. There are nine alterntive scenarios focusing on technical, operational, adminsitrative and commercial in reducing the BOR level of the terminal including optimising the level of throughput achieving at 32 million tons of oil and gas related cargo. 


\begin{tabular}{|c|l|}
\hline No & \multicolumn{1}{|c|}{ Scenario Model } \\
\hline 1 & The pattern of arrival of the vessel accelerated 30\% \\
\hline 2 & The pattern of arrival of the vessel accelerated 50\% \\
\hline 3 & $\begin{array}{l}\text { The pattern of arrival of the vessel accelerated 50\% + Increasing of capacity MLA until 150\% at each } \\
\text { Jetty }\end{array}$ \\
\hline 4 & $\begin{array}{l}\text { The pattern of arrival of the vessel accelerated 50\% + Increasing of capacity MLA until 200\% at each } \\
\text { Jetty }\end{array}$ \\
\hline 5 & The pattern of arrival of the vessel accelerated 50\% + Decreasing of Waiting Time 10\% (Document) \\
\hline 6 & $\begin{array}{l}\text { The pattern of arrival of the vessel accelerated 50\% + Decreasing of Waiting Time 30\% (Document + } \\
\text { Hose connect \& disconnect + Berthing \& Unberthing) }\end{array}$ \\
\hline 7 & $\begin{array}{l}\text { The pattern of arrival of the vessel accelerated 50\% + Decreasing of Waiting Time 50\% (Document + } \\
\text { Hose connect \& disconnect + Berthing \& Unberthing + Waiting for pilot vessel) }\end{array}$ \\
\hline 8 & $\begin{array}{l}\text { The pattern of arrival of the vessel accelerated 50\% + Decreasing of Waiting Time 50\% (Document + } \\
\text { Hose connect \& disconnect + Berthing \& Unberthing + Waiting for pilot vessel)+ Increasing of } \\
\text { capacity MLA until 200\% at each Jetty }\end{array}$ \\
\hline 9 & $\begin{array}{l}\text { The pattern of arrival of the vessel accelerated 50\% + Decreasing of Waiting Time 50\% (Document + } \\
\text { Hose connect \& disconnect + Berthing \& Unberthing + Waiting for pilot vessel)+ Increasing of } \\
\text { capacity MLA until 200\% in each Jetty + Increacing Capicity of Vessel's Cargo + adding metering at } \\
\text { each Jetty }\end{array}$ \\
\hline
\end{tabular}

\section{CONCLUSION}

From the experimental result of scenario 1 and 2, BOR Value in "high" category for all jetties except Jetty 5 A. And from the total cargo in scenario 1 and 2 not yet to fulfill commercial plan in 2020,32 million tons. So it can be said that scenario 1 and 2 rejected. Further, if scenarios 3 and 4 analysed then the BOR value is calculated as high category for all jetties except Jetty 5A. so it can be said that scenario 3 and 4 like scenario 1 and 2, are rejected. Similarly, From the experimental result of scenario 4,5 and 6, BOR Value and total cargo like previous scenarios. So it can be said that scenario 5,6 , and 7 are also rejected. Furter, isf scenaro 8 is analysed, it is stated that of scenario 8 can get the information that generate lower BOR Value compared to previous scenarios. However, the total cargo in scenario 8 is unable to fulfill commercial plan in 2020, which is about 32 million tons. So it can be said too that scenario 8 like previous scenarios are further rejected. Finally, scenario 9 is the only effort that may generate a lower BOR including fulfill the commercial plan throughput in 2020 which is about 32 million tons. Therefore, it can be stated that scenario 8 is fully accepted.

\section{REFERENCE}

[1] S. Tewari, "Optimization of port capacity - a study of Vadinar oil terminal.," University of Petroleum \& Energy Studies, 2009.

[2] M. M. Golias, G. K. Saharidis, M. Boile, S. Theofanis, and M. G. Ierapetritou, "The berth allocation problem: Optimizing vessel arrival time," Marit. Econ. Logist., vol. 11, no. 4, pp. 358-377, Dec. 2009.

[3] J. D. Griffiths, "Optimal handling capacity at a berth," Marit. Stud. Manag., vol. 3, no. 3, pp. 163-167, Jan. 1976.

[4] G. G. Brown, S. Lawphongpanich, and K. P. Thurman, "Optimizing ship berthing," Nav. Res. Logist., vol. 41, no. 1, pp. 1-15, Feb. 1994.

[5] A. M. . Soberon, "Assessing port performance: the capacity in container port terminals, Ad Hoc expert meeting report.," Geneva, 2012.

[6] S. Bassan, "Evaluating seaport operation and capacity analysis - preliminary methodology," Marit. Policy Manag., vol. 34, no. 1, pp. 3-19, Feb. 2007. 